\title{
CAUSALES DE INADMISIBILIDAD DE OPINIONES CONSULTIVAS: REFORZANDO EL CARÁCTER SUBSIDIARIO DEL SISTEMA INTERAMERICANO DE DERECHOS HUMANOS
}

\author{
REFUSING TO RENDER ADVISORY OPINIONS: REINFORCING THE \\ SUBSIDIARY CHARACTER OF THE INTER-AMERICAN SYSTEM OF \\ HUMAN RIGHTS PROTECTION
}

\section{GonZalo Candia Falcón*}

RESUMEN: El autor propone que la Corte Interamericana de Derechos Humanos, por medio del establecimiento de causales para declarar inadmisibles solicitudes de opinión consultiva, ha buscado proteger el carácter subsidiario del sistema regional de protección de derechos. Sin embargo, el artículo también demuestra que la Corte, recientemente, no ha sido completamente coherente con su propia doctrina en esta materia.

Palabras clave: Corte Interamericana de Derechos Humanos, función consultiva, principio de subsidiariedad, causales de inadmisibilidad, control de convencionalidad.

ABSTRACT: The author proposes that the reasons developed by the Inter-American Court of Human Rights to reject requests of advisory opinions seek to preserve the subsidiary character of the regional system of human rights. However, the article shows recent cases in which the Court has not been completely consistent with its own previous decisions on this matter.

Keywords: Inter-American Court of Human Rights, advisory opinions, subsidiarity, reasons of inadmissibility, conventionality control.

\section{INTRODUCCIÓN}

De acuerdo al artículo 64 de la Convención Americana sobre Derechos Humanos -en adelante, "la Convención"-, la Corte Interamericana de Derechos Humanos -en adelante, CIADH o la Corte-, dispone de facultades de carácter consultivo. Esto es, facultades para pronunciar opiniones cuando un estado o un órgano del sistema regional de protección de derechos humanos así lo soliciten. Ahora bien, en conformidad al señalado artículo, el propósito de las opiniones consultivas es doble. Por un lado, a través de ellas la CIADH responde consultas acerca de "la interpretación de [la] Convención o de otros tratados concernientes a la protección de los derechos humanos en los estados americanos". Por otro, la CIADH por medio de una opinión consultiva puede pronunciarse respecto de

\footnotetext{
* Doctor en Derecho (S.J.D.) por la Universidad de Georgetown. Profesor de Derecho Constitucional y Derechos Humanos, Pontificia Universidad Católica de Chile. Dirección postal: Alameda del Libertador Bernardo O’Higgins 340, Santiago de Chile. Correo electrónico: gfcandia@uc.cl. El autor agradece la colaboración prestada por René Tapia, ayudante de cátedra, en la redacción del presente trabajo.
} 
"la compatibilidad entre [las] leyes internas [de los estados] y los mencionados instrumentos internacionales".

En relación con el alcance, esta facultad, la CIADH ha manifestado que la misma le otorga "la más amplia función consultiva que se haya confiado a tribunal internacional

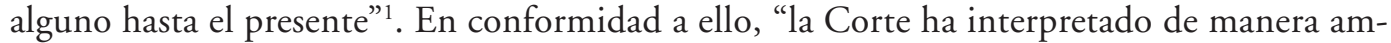
plia y extensiva su competencia consultiva, de modo que la misma sirva para asegurar de la manera más eficiente los fines del sistema regional de protección"2. Pese al referido reconocimiento, la misma CIADH ha manifestado que "la amplitud de los términos del artículo 64 de la Convención no puede (...) confundirse con la ausencia de límites a la función consultiva" 3 .

Con el propósito de fijar límites al ámbito de ejercicio de esta función, la CIADH ha establecido en su jurisprudencia una serie de causales de inadmisibilidad que le permiten rechazar solicitudes de opinión consultiva requeridas tanto por los estados como por otros órganos del sistema de protección interamericano. La tesis central que será defendida en el presente artículo es que las referidas causales de inadmisibilidad buscan, en su conjunto, custodiar el carácter subsidiario del sistema regional de protección de derechos humanos. Esto último, en la medida que la propia CIADH ha afirmado que el ejercicio de su función consultiva "no puede desvincularse de los propósitos de la Convención” ${ }^{4}$, por tanto, su ejercicio no podría contrariar la "finalidad coadyuva[nte]" del tratado5.

Invocando alguna de las causales de inadmisibilidad en cuestión, la CIADH ha rechazado pronunciarse sobre consultas efectuadas por los estados o bien por otros actores del sistema regional en cinco ocasiones. En cada uno de estos casos es posible advertir el interés de la Corte por preservar el carácter subsidiario del esquema de protección interamericano. Sin perjuicio de lo anterior, la CIADH, a partir de 1999, ha dictado una serie de pronunciamientos que no son completamente coherentes con su propia doctrina en estas materias. En efecto, la CIADH, buscando ampliar el ámbito de ejercicio de su función consultiva, ha terminado por impactar negativamente la naturaleza subsidiaria del sistema en la medida que: (a) ha utilizado el mecanismo en cuestión para efectuar pronunciamientos genéricos sobre políticas públicas y (b) ha dotado de carácter general y obligatorio al contenido de las opiniones consultivas. En relación con la estructura interna del artículo, este se desarrollará a través de cuatro secciones que buscarán: (i) explicar cómo el principio de subsidiariedad estructura las bases del sistema interamericano; (ii) describir las causales de inadmisibilidad establecidas por la CIADH en relación a las solicitudes de opiniones consultivas; (iii) referir la forma cómo cada una de dichas causales busca proteger la natu-

\footnotetext{
1 Opinión Consultiva OC-1/82 “Otros tratados" objeto de la función consultiva de la Corte (artículo 64 de La CONVENCIÓn Americana sobre Derechos Humanos), párrafo 14.

2 NikKen (1998) p. 171.

3 Opinión Consultiva OC-1/82 "Otros tratados" objeto de la función consultiva de la Corte (artículo 64 DE LA CONVENCIÓN AMERICANA SOBRE DERECHOS HuMANOS), párrafo 18.

4 Opinión Consultiva OC-1/82 “Otros tratados" objeto de la función consultiva de la Corte (artículo 64 DE LA CONVENCIÓN AMERICANA SOBRE DERECHOS HuMANOS), párrafo 25.

5 Opinión Consultiva OC-1/82 “Otros tratados" objeto de la función consultiva de la Corte (artículo 64 de la CONVENCión Americana sobre Derechos Humanos), párrafo 25.
} 
raleza subsidiaria del sistema regional de protección de derechos humanos; y (iv) analizar cuán consistente ha sido la CIADH en la aplicación de su propia jurisprudencia en relación a este punto.

\section{EL PRINCIPIO DE SUBSIDIARIEDAD Y EL SISTEMA INTERAMERICANO DE PROTECCIÓN DE DERECHOS HUMANOS}

La Corte ha afirmado en varias oportunidades el carácter subsidiario y coadyuvante del sistema de protección interamericano de derechos humanos ${ }^{6}$. En virtud de aquel, los órganos regionales del sistema interamericano y los estados parte deben asumir responsabilidades diferenciadas y escalonadas en relación con la protección de los derechos reconocidos por la Convención. Así, corresponde a los estados asumir la responsabilidad de "asegurar la implementación de la Convención Americana a nivel nacional" . Mientras tanto, corresponde a los órganos del sistema -la Comisión y la Corte- otorgar protección complementaria a los derechos reconocidos en el tratado únicamente cuando los estados no sean capaces de garantizarlos, ya sea por error, negligencia o directa infracción por parte de aquellos.

La CIADH ha establecido lo anterior de forma clara en el caso LAS PALMERAS V. COLOMBIA. En dicha oportunidad, la Corte manifestó que el sistema regional de protección de derechos humanos consta de dos niveles. El primero de ellos es el nacional. Dentro de este nivel los estados tienen la responsabilidad de "garantizar los derechos y libertades previstos en la Convención y de sancionar las infracciones que se cometieren" ${ }^{\prime}$. El segundo nivel es el internacional. Este último estaría llamado a operar únicamente cuando "un caso concreto [de derechos humanos] no es solucionado en la etapa interna o nacional" . De allí que, de acuerdo a la propia Convención, la jurisdicción de la CIADH sea "coadyuvante o complementaria (...) [a] la que ofrece el derecho interno de los estados americanos" ${ }^{10}$. Es por ello que la Corte puede declarar la responsabilidad estatal "solo (...) después de que el estado haya tenido oportunidad de examinarla y declararla a través de los recursos de la jurisdicción interna y de reparar el daño ocasionado" 11 .

Ahora bien, los valores que el principio de subsidiariedad busca custodiar en la esfera internacional son diversos. En primer lugar, la aplicación de la subsidiariedad en esta esfera tiene por objetivo proteger los justos espacios de autonomía propios de toda comunidad políticamente organizada ${ }^{12}$. Ello por medio del reconocimiento del papel primario que corresponde representar a los estados en la protección de los derechos humanos vis a vis con las autoridades regionales. En efecto, son los estados los primeros llamados a asumir la

\footnotetext{
6 Por ejemplo: CAso ACEVEDo JARAmillo V. PERÚ (2006) párrafo 66. Para un análisis de la aplicación del principio de subsidiariedad en el contexto del sistema de protección europeo, ver: MowbraY (2015).

7 Caso AceVedo Jaramillo v. Perú (2006) párrafo 66.

8 Las palmeras v. Colombia (2001) párrafo 33.

9 Las palmeras v. Colombia (2001) párrafo 33.

10 Las Palmeras v. Colombia (2001) párrafo 33.

11 RIOS Y OTROS V. VENEZUELA (2009) párrafo 53.

12 Finnis (2016) p. 134.
} 
responsabilidad de garantizar y proteger los derechos humanos de quienes residen dentro de sus respectivas jurisdicciones, adoptando "las medidas legislativas o de otro carácter que fueren necesarias para hacer efectivos tales derechos y libertades", según reza el artículo $2^{\circ}$ de la Convención. Ello en el entendido que el estado "es el principal garante de los derechos humanos de las personas"13. Esto, básicamente, porque son los estados -esto es, las comunidades políticamente organizadas- quienes disponen de los mecanismos normativos, técnicos y financieros necesarios para otorgar una protección global a los derechos de sus propios ciudadanos. Desde esa perspectiva, resultaría injusto que un órgano externo a él se arrogue una responsabilidad que el propio estado está habilitado per se para asumir. Esa injusticia se produciría en la medida que se privaría a una comunidad políticamente organizada de la posibilidad de autorrealización y autogobierno implícita en la idea de subsidiariedad.

En ese contexto, corresponderá a las instituciones regionales, como la Corte o la Comisión Interamericana, intervenir únicamente cuando los estados no asuman su responsabilidad de protección. Desde esa perspectiva, la labor de las instituciones regionales es apoyar a los estados en sus esfuerzos por dar cumplimiento a las obligaciones internacionales de derechos humanos adquiridas por estos en virtud de la ratificación de la Convención. Es por ello que la propia CIADH ha manifestado que "la responsabilidad estatal bajo la Convención solo puede ser exigida a nivel internacional después de que el estado haya tenido la oportunidad de declarar la violación y reparar el daño ocasionado por sus propios medios" 14 .

Por otro lado, la doctrina de la subsidiariedad aplicada en el contexto del derecho internacional de los derechos humanos tiene un valor relevante desde la perspectiva de la democracia y el autogobierno ${ }^{15}$. Tal como se mencionó anteriormente, la Convención contiene una multiplicidad de estándares de derechos humanos cuya implementación dentro de la normativa interna de los estados requiere necesariamente de la generación de reglas específicas que permitan especificar su ejercicio "en conformidad con las justas exigencias del bien común”, según lo manifiesta el artículo 32.2 de la Convención.

Ahora bien, dentro de los estados, los llamados primariamente a asumir esa responsabilidad son las legislaturas democráticamente elegidas a través de procedimientos transparentes y determinados ${ }^{16}$. De esa forma, los intereses de quienes serán los destinatarios de las normas jurídicas son suficientemente considerados y, simultáneamente, quienes deciden están sujetos a reglas de responsabilidad política, lo que promueve el ideal democrático de control de la autoridad ${ }^{17}$.

13 Caso Acevedo Jaramillo V. Perú (2006) párrafo 66.

14 Masacre de Santo Domingo v. Colombia (2012) párrafo 142.

15 Donoho (2003) pp. 21-25.

16 Opinión Consultiva OC-6/86 "LA EXPRESIÓN LEYES EN EL ARTÍCUlo 30 de LA CONVENCIÓN AMERICANA SOBRE DERECHOS HUMANOS", párrafo 38.

17 Opinión CONSUltiva OC-6/86 "LA EXPRESIÓN LEYES EN EL ARTÍCUlo 30 dE LA CONVENCIÓN AMERICANA SOBRE DERECHOS HUMANOS”, párrafo 22. Para una precisión crítica de esta doctrina, véase: OPINIÓN CONSULTIVA OC-24/17 "IDENTidad de GÉNero, e IGUAldad y No Discriminación a PARejas del Mismo SeXo", voto concurrente del Juez Humberto Sierra Porto, párrafos 20-31. 
Finalmente, la aplicación del principio de subsidiariedad en el ámbito del derecho internacional de los derechos humanos tiene una doble vertiente: una procedimental y una sustantiva ${ }^{18}$. La vertiente procedimental de la subsidiariedad busca proteger, esencialmente, los espacios de decisión reservados a los tribunales nacionales frente a la acción de los tribunales internacionales de derechos humanos ${ }^{19}$. En razón de aquella exigencia procedimental es que la $\mathrm{CIADH}$ ha rechazado constituirse en "un tribunal (...) de apelación para dirimir los desacuerdos que tengan las partes sobre determinados alcances de la aplicación del derecho interno en aspectos que no estén directamente relacionados con el cumplimiento de obligaciones internacionales en derechos humanos" ${ }^{20}$. Por otro lado, la vertiente sustantiva de la subsidiariedad exige que se reconozca a los estados la potestad de implementar el contenido fundamental de las obligaciones correlativas a los derechos establecidos en los tratados internacionales de derechos humanos en conformidad a lo que los mismos estados definan como las justas exigencias del bien común ${ }^{21}$. Esta vertiente sustantiva ha sido reconocida por la CIADH de manera un poco más tímida, a través de la identificación de un margen de apreciación en favor de los estados, el que les permite a aquellos disponer de una razonable discrecionalidad para implementar las garantías convencionales ${ }^{22}$.

En conclusión: la Corte, interpretando y aplicando el texto de la Convención: (a) ha reconocido el carácter subsidiario del sistema de protección regional de derechos humanos y (b) ha aceptado que el principio de subsidiariedad es el criterio que permite distinguir conceptualmente los ámbitos de responsabilidad tanto de los estados como de las instituciones regionales en relación al deber de protección de los derechos humanos reconocidos por la Convención.

\section{SUBSIDIARIEDAD Y OPINIONES CONSULTIVAS: LA NECESIDAD DE PRESERVAR LOS ESPACIOS DE DELIBERACIÓN POLÍTICA Y LOS RAZONABLES MÁRGENES DE DISCRECIONALIDAD DE LOS ESTADOS}

Según se señaló anteriormente, la CIADH ha reconocido que el principio de subsidiariedad representa un criterio primario para definir los ámbitos de autoridad de los diversos actores que integran el sistema regional de protección de derechos humanos. En razón de aquello, la CIADH ha establecido en su jurisprudencia una serie de causales de inadmisibilidad que le permiten rechazar pronunciarse respecto de solicitudes de opinión consultiva requeridas por los estados u otros órganos del sistema.

Así, la CIADH considerando las exigencias procedimentales de la subsidiariedad, ha establecido que son inadmisibles las solicitudes de opinión de consultiva que busquen resolver asuntos propios de la jurisdicción contenciosa de la Corte o bien que busquen definir situaciones de hecho asociadas a casos de derechos humanos. De igual forma, la

\footnotetext{
BESSON (2016) p. 78.

19 Besson (2016) pp. 79-80.

20 PALMA MENDOZA Y OtROS V. ECUADOR (2012) párrafo 16.

21 Besson (2016) pp. 80-83.

22 LEGG (2012) pp. 31-33.
} 
CIADH, buscando realizar las exigencias sustantivas de la subsidiariedad, ha afirmado que resulta inadmisible toda solicitud de opinión consultiva que busque obtener un pronunciamiento cuyo contenido pudiese intervenir indebidamente en el debate legislativo interno de cada estado, o bien que significara emitir una opinión acerca de la validez del derecho nacional ${ }^{23}$.

\subsection{Causales de inadmisibilidad Vinculadas a las eXigenCias de la SUbSidiariedad} PROCEDIMENTAL

En primer lugar, la Corte ha declarado que ciertas solicitudes de opiniones consultivas deben ser declaradas inadmisibles en la medida que aquellas "encubr[an] un caso contencioso o pretend[an] obtener prematuramente un pronunciamiento sobre un tema o asunto que podría ser eventualmente sometido a la Corte a través de un caso contencioso" 24 . Por tanto, la Corte tiene la obligación de declarar inadmisible toda solicitud de opinión consultiva que genere como resultado "una solución de manera encubierta, por la vía de la opinión consultiva, de asuntos litigiosos aun no sometidos a consideración de la Corte"25.

Las razones invocadas por la Corte para declarar inadmisibles el tipo de peticiones referidas tienen relación con potenciales infracciones del debido proceso tanto respecto del estado en cuestión como de la supuesta víctima, quienes en el contexto del procedimiento propio de una opinión consultiva no podrían ejercer adecuadamente sus derechos procesales $^{26}$. Sin embargo, también es posible entender esta causal de inadmisibilidad desde una perspectiva subsidiaria. En efecto, cuando la Corte declara inadmisible una solicitud de opinión consultiva respecto de una materia de naturaleza contenciosa, aquel tribunal no hace sino proteger el carácter subsidiario del sistema regional de protección de derechos humanos.

Ello por cuanto todo asunto litigioso de derechos humanos, cualquiera sea este, debe ser primeramente conocido y resuelto por los tribunales de justicia nacionales en el contexto de un debido proceso, tal como se deduce del artículo 46.1 de la Convención. Solo una vez que se produzca el agotamiento de los recursos jurisdiccionales domésticos corresponderá a los órganos del sistema regional de derechos humanos la Comisión o la Corte, según sea el caso intervenir en el asunto. Desde esa perspectiva, si un estado solicita una opinión consultiva a la Corte respecto de una situación cuya naturaleza es esencialmente litigiosa, lo que hace es forzar un pronunciamiento de la Corte respecto de una controversia de derechos humanos que debe ser objeto del conocimiento de los tribunales de justicia

23 Para una descripción reciente de las causales señaladas, véase: PAÚl (2017) pp. 121-129.

24 OPINIÓN CONSULTIVA OC-16/99 "EL DERECHO A LA INFORMACIÓN SOBRE LA ASISTENCIA CONSULAR EN EL MARCO DE LAS GARANTIAS DEL DEBIDO PROCESO”, párrafo 45.

25 Opinión Consultiva OC-12/91 "Compatibilidad dE UN PROYECTO DE LEY CON EL ARTÍCUlo 8.2. H DE LA CONVENCIÓN AMERICANA SOBRE DERECHOS HuMANOS”, párrafo 28.

26 OPINIÓN CONSULTIVA OC-14/94 "RESPONSABILIDAD INTERNACIONAL POR EXPEDICIÓN Y APLICACIÓN DE LEYES VIOLA-

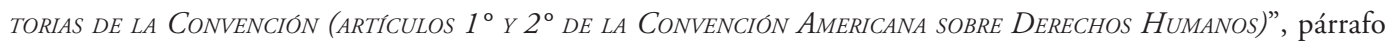
28. Véase también: OPINIÓN CONSUltiva OC-24/17 "IDENTIDAD DE GÉNERO, E IGUALDAD Y NO DisCRIMINACIÓN A PARejAS DEL Mismo SEXo”, voto individual del Juez Eduardo Vío Grossi, párrafo 149. 
nacionales en primer lugar. Por tanto, la Corte podrá intervenir únicamente cuando sean satisfechas todas las demandas de la subsidiariedad en relación a este punto y siempre en el contexto del ejercicio de su jurisdicción contenciosa.

En segundo lugar, la Corte ha afirmado que debe ser declarada inadmisible toda solicitud de opinión consultiva que fuerce al tribunal a pronunciarse respecto a la resolución de cuestiones de hecho ${ }^{27}$. Ello en la medida que el ejercicio de la jurisdicción consultiva únicamente "busca desentrañar el sentido, propósito y razón de las normas internacionales de derechos humanos"28.

Esta causal de admisibilidad también busca preservar el carácter subsidiario del sistema regional de derechos humanos. Es responsabilidad de los tribunales del estado, en el contexto de un debido proceso, resolver cuestiones de hecho asociadas a casos de derechos humanos y corregir errores respecto de esas cuestiones durante los procedimientos correspondientes. Por tanto, tal como la propia Corte lo ha afirmado permanentemente, no es su deber resolver este tipo de disputas, sino determinar la responsabilidad internacional de los estados en casos que estos infrinjan derechos reconocidos por la Convención. Ello en la medida que la jurisdicción de la Corte, en términos generales, busca apoyar y complementar el papel desempeñado por los tribunales nacionales, no reemplazarlos ${ }^{29}$. Por tanto, la causal de inadmisibilidad descrita está asociada íntimamente a las exigencias propias del carácter subsidiario del sistema.

\subsection{CAUSALES DE INADMisibilidAD VINCULADAS A LAS EXIGENCIAS DE LA SUBSIDIARIEDAD}

\section{SUSTANTIVA}

En primer lugar, la Corte ha señalado que deben ser declaradas inadmisibles todas aquellas solicitudes de opinión consultiva que potencialmente puedan ser utilizadas al interior de los estados como "instrumento de un debate político con el fin de afectar el resultado del proceso legislativo interno" ${ }^{30}$. Esta causal de inadmisibilidad referida por la Corte también exhibe una particular sensibilidad por la necesidad de preservar el carácter subsidiario del sistema regional de derechos humanos.

En efecto, en conformidad a lo señalado por el artículo $2^{\circ}$ de la Convención son los estados los llamados a "a adoptar (...) las medidas legislativas o de otro carácter que fueren necesarias para hacer efectivos (...) derechos y libertades”, especificando los mismos a través de un proceso normativo que busque armonizarlos con otras "justas exigencias del bien común”, según indica el artículo 32.2 de la Convención.

Ahora bien, este proceso de especificación legislativa de los derechos es, de acuerdo a lo establecido en la Convención, responsabilidad de los estados. Corresponde a ellos, y no a los órganos del sistema regional, asumir este deber. En virtud de aquello, la propia Corte

\footnotetext{
27 OPINIÓN CONSULTIVA OC-16/99 "EL DERECHO A LA INFORMACIÓN SOBRE LA ASISTENCIA CONSULAR EN EL MARCO DE LAS GARANTIAS DEL DEBIDO PROCESO”, párrafo 47.

28 OPINIÓN CONSULTIVA OC-16/99 "EL DERECHO A LA INFORMACIÓN SOBRE LA ASISTENCIA CONSULAR EN EL MARCO DE LAS GARANTIAS DEL DEBIDO PROCESO”, párrafo 47.

29 Caso Cabrera García Y MONTIEL FLoRes V. MÉXICO (2010) párrafo 16.

30 Opinión Consultiva OC-4/84 "Propuesta de modificación a la Constitución Política de Costa Rica relaCIONADA CON LA NATURALIZACIÓN”, párrafo 26.
} 
ha reconocido, en el ejercicio de su función consultiva, un alto grado de autonomía a los estados en el contexto de este proceso ${ }^{31}$. Ello en la medida que aquella ha afirmado que ciertas materias se encuentran "reservadas al dominio exclusivo del derecho interno" 32 y que los estados gozan de un margen de apreciación razonable para especificar los estándares de derechos humanos amplios y generales contenidos en la Convención ${ }^{33}$. Estos criterios son absolutamente coherentes con las demandas de la subsidiariedad en el ámbito del proceso de especificación de derechos. En efecto, son los estados quienes tienen la responsabilidad de delimitar el ámbito de ejercicio de los derechos reconocidos por la Convención.

Ahora bien, la Corte ha señalado que dicho proceso de especificación de derechos corresponde eminentemente al legislador nacional ${ }^{34}$. Por medio de dicho proceso, el legislador procederá a determinar "las responsabilidades y sanciones que fueren necesarias" 35 para armonizar el ejercicio de los derechos reconocidos en la Convención.

La Corte asigna la responsabilidad primaria de especificar los derechos contenidos en la Convención al legislador nacional por dos razones. La primera de ellas es que las regulaciones del legislador acerca de los derechos están investidas del "asentimiento de la representación popular" ${ }^{36}$ y cuentan, por tanto, con toda la fuerza que les otorga su legitimidad democrática. Por otro lado, la Corte confía al Poder Legislativo la especificación de los derechos en razón de las especiales características del proceso legislativo, el que permite "a las minorías expresar su inconformidad, proponer iniciativas distintas, participar en la formación de la voluntad política o influir sobre la opinión pública para evitar que la mayoría actúe arbitrariamente" ${ }^{37}$. Desde esa perspectiva, la reserva legal en materia de regulación de derechos fundamentales representa "un obstáculo importante para el ejercicio arbitrario del poder" 38 .

En ese sentido, la Corte contrasta el carácter abierto, público y transparente del proceso legislativo con la opacidad de los procesos asociados al Poder Ejecutivo. En efecto, "la protección de los derechos humanos requiere que los actos estatales que los afecten de manera fundamental no queden al arbitrio del poder público, sino que estén rodeados de un conjunto de garantías enderezadas a asegurar que no se vulneren los atributos inviolables de

\footnotetext{
31 Pasqualucci (2012) p. 51.

32 Opinión Consultiva OC-4/84 "Propuesta de modificación a la Constitución Política de Costa Rica RelaCIONADA CON LA NATURALIZACIÓN”, párrafo 61.

33 Opinión Consultiva OC-4/84 "Propuesta de modificación a la Constitución Política de Costa Rica RelaCIONADA CON LA NATURALIZACIÓN”, párrafo 62.

34 Opinión CONSUltiva OC-6/86 "LA EXPRESIÓN LEYES EN EL ARTICULO 30 DE LA CONVENCIÓN AMERICANA SOBRE DERECHOS HUMANOS”, párrafo 32. Con relación a las razones normativas de esta preferencia institucional, ver también: Hessler (2005) pp. 42-45.

35 Opinión Consultiva OC-6/86 "LA EXPRESIÓN LEYES EN EL ARTÍCUlo 30 dE LA CONVENCIÓN AMERICANA SOBRE DERECHOS HUMANOS", párrafo 31.

36 Opinión Consultiva OC-6/86 "LA EXPResión leyes en el artículo 30 de la CONVENCión AmERICANA SOBRE DERECHOS HUMANOS", párrafo 22.

37 Opinión CONSUltiva OC-6/86 "LA EXPRESIÓN LEYES EN EL ARTÍCULO 30 DE LA CONVENCIÓN AMERICANA SOBRE DERECHOS HUMANOS”, párrafo 22.

38 OpINión CONSUltiva OC-6/86 "LA EXPRESIÓN LEYES EN EL ARTÍCULO 30 DE LA CONVENCIÓN AMERICANA SOBRE DERECHOS HUMANOS", párrafo 22.
} 
la persona" 39 . En este contexto, la regulación del ejercicio de derechos por parte del poder ejecutivo "equivaldría a reconocer una virtualidad absoluta a los poderes de los gobernantes frente a los gobernados" 40 .

En el contexto de la discusión legislativa abierta, pública y transparente en torno a las exigencias de los derechos es posible que surjan desacuerdos entre quienes participan de este proceso. En ese caso, será responsabilidad de los actores legislativos nacionales resolver ese desacuerdo por medio de una solución de compromiso que, reafirmando la regla de la mayoría, proteja simultáneamente los intereses más relevantes de la minoría ${ }^{41}$. Para la Corte es esencial que dicho proceso sea llevado a cabo de un modo tal que aquel pueda expresar de forma razonable la voluntad popular. Con el propósito de proteger este proceso de interferencias anómalas, la CIADH ha establecido que cuando existan "disputas políticas internas" ${ }^{42}$ en torno a temáticas de derechos humanos, este tribunal "no debe inmiscuirse" 43 en ellas por medio del pronunciamiento de una opinión consultiva. Esto porque una intervención de ese carácter podría "afectar el papel que la Convención le asigna" ${ }^{44}$ a la CIADH dentro del sistema regional de protección de derechos. Ahora bien, en la medida que la Corte evita inmiscuirse en el proceso legislativo nacional, protege la justa autonomía del mismo y, de esta forma, realiza el principio de subsidiariedad en su dimensión de autogobierno. En ese sentido, y tal como lo afirmó el juez Sergio García Ramírez, el tribunal interamericano " $\mathrm{n}[\mathrm{o}]$ es foro para la confrontación política entre las fuerzas que disputan el poder en un país, que pueden y deben zanjar sus diferencias por la vía democrática interna" ${ }^{\$ 5}$.

Por tanto, si la Corte recibe una solicitud de opinión consultiva que pueda ser utilizada dentro de los estados como "instrumento de[1] debate político con el fin de afectar el resultado del proceso legislativo interno" ${ }^{46}$, la misma debe ser declarada inadmisible por el tribunal interamericano.

En segundo lugar, la Corte ha señalado que el ejercicio de su jurisdicción consultiva no puede tener por finalidad "interpretar o definir los ámbitos de validez de las leyes internas de los estados” ${ }^{47}$. Esto porque, a partir del artículo 64.2 de la Convención, corresponde únicamente a la Corte pronunciarse acerca de la compatibilidad de la legislación interna

\footnotetext{
39 OPINIÓN CONSULTIVA OC-6/86 "LA EXPRESIÓN LEYES EN EL ARTICULL 30 DE LA CONVENCIÓN AMERICANA SOBRE DERECHOS HUMANOS", párrafo 22.

40 OPINIÓN CONSUltiva OC-6/86 "LA EXPRESIÓN LEYES EN EL ARTÍCULO 30 DE LA CONVENCIÓN AMERICANA SOBRE DERECHOS HUMANOS", párrafo 27.

41 WaLdRON (1999) pp. 235-239.

42 Opinión Consultiva OC-4/84 "Propuesta de modificación a la Constitución Política de Costa Rica RelaCIONADA CON LA NATURALIZACIÓN”, párrafo 30.

43 Opinión Consultiva OC-4/84 "Propuesta de modificación a la Constitución Politica de Costa Rica relaCIONADA CON LA NATURALIZACIÓN”, párrafo 30.

44 Opinión Consultiva OC-4/84 "Propuesta de modificación a la Constitución Política de Costa Rica RelaCIONADA CON LA NATURALIZACIÓN”, párrafo 30.

45 Opinión Consultiva OC-20/09 "Artículo 55 de la Convención Americana sobre Derechos Humanos", voto concurrente del Juez Sergio García Ramírez, párrafo 83.

46 Opinión Consultiva OC-4/84 "Propuesta de modificación a la Constitución Política de Costa Rica RelaCIONADA CON LA NATURALIZACIÓN”, párrafo 26.

47 OPINIÓN CONSULTIVA OC-14/94 "RESPONSABILIDAD INTERNACIONAL POR EXPEDICIÓN Y APLICACIÓN DE LEYES VIOLATOrias de la Convención (artículos $1^{\circ}$ Y $2^{\circ}$ DE LA Convención Americana sobre Derechos Humanos)”, párrafo 22.
} 
con lo establecido en la Convención, siempre que medie para ello una solicitud expresa de algún estado ${ }^{48}$. Al igual que la causal de inadmisibilidad vinculada a la resolución de cuestiones de hecho, esta causal busca evitar que la Corte asuma responsabilidades que corresponden de suyo a las autoridades nacionales, quienes son los órganos llamados a interpretar y aplicar el derecho nacional dentro del ámbito de su competencia.

\subsection{Subsidiariedad y EFECTOS DE LAS Opiniones CONSUltivas}

Finalmente, la Corte se ha servido del carácter subsidiario del sistema regional de protección de derechos humanos para delimitar los efectos de sus opiniones consultivas. En efecto, la Corte ha afirmado que sus opiniones consultivas "no tienen el mismo efecto vinculante que se reconoce para sus sentencias en materia contenciosa" ${ }^{\prime 2}$. Ello en la medida que las opiniones en cuestión cumplen una "función asesora" ${ }^{50}$ en relación a los estados. Así, la Corte busca por medio de las opiniones consultivas "ayudar a los estados miembros (...) para que cumplan de manera cabal y efectiva sus obligaciones internacionales" 51 en materia de derechos humanos. Esa ayuda tiene naturaleza coadyuvante; esto es, no busca reemplazar, sino apoyar al estado en el cumplimiento de sus propias responsabilidades dentro del sistema regional de protección de derechos.

En conformidad a lo anterior, la interpretación que haga la Corte de un precepto de la Convención o bien el análisis de compatibilidad que efectúe aquella en relación a la legislación o proyecto de ley nacional no puede representar un mandato absoluto y definitivo para el estado, sino una orientación necesaria que puede buscar, en muchos casos, iniciar una suerte de diálogo regional sobre temáticas de derechos humanos controvertidas. Ello por cuanto la propia Corte ha reconocido, en el contexto del ejercicio de su función consultiva, que los estados gozan de un margen de apreciación razonable con relación a la forma como implementan los estándares de derechos humanos contenidos en la Convención ${ }^{52}$.

En el escenario anteriormente descrito es posible también analizar el valor jurídico de las opiniones consultivas pronunciadas por la CIADH. Para la gran mayoría de la doctrina, el valor de aquellas deriva eminentemente de la fuerza moral y científica del órgano que las pronuncia ${ }^{53}$. Sin embargo, es necesario rechazar el argumento de autoridad expuesto. La real fuerza directiva que poseen las opiniones consultivas no deriva del solo hecho que sean emitidas por la CIADH, sino de la calidad de las razones ofrecidas por la Corte a los estados o a los demás órganos del sistema para actuar. Es precisamente esa calidad y

\footnotetext{
48 OPINIÓN CONSULTIVA OC-14/94 "RESPONSABILIDAD INTERNACIONAL POR EXPEDICIÓN Y APLICACIÓN DE LEYES VIOLAtorias de la Convención (artículos $1^{\circ}$ Y $2^{\circ}$ DE LA ConVEnción Americana sobre Derechos Humanos)”, párrafo 22.

49 Opinión Consultiva OC-1/82 "Otros tratados" objeto de la función consultiva de la Corte (artículo 64 DE LA CONVENCIÓN AmERICANa SOBRE DeRECHOS Humanos), párrafo 51.

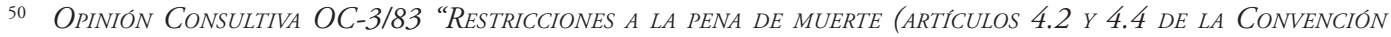
AMERICANA SOBRE DERECHOS HuMANOS)”, párrafo 32.

51 Opinión Consultiva OC 13/93 “Ciertas atribuCiones de la Comisión Interamericana de Derechos Humanos (artículos 41, 42, 44, 46, 47, 50 y 51 de la CONVENCIÓN AmeriCANa sobre DereChos Humanos)”, párrafo 23.

52 Opinión Consultiva OC-4/84 "Propuesta de modificación a la Constitución Política de Costa Rica RelaCIONADA CON LA NATURALIZACIÓN”, párrafo 62.

53 Ver: Pasqualucci (2012) p. 37; Burgorgue-Larsen y Úbeda de Torres (2011) p. 90; Hitters (2008) p. 149.
} 
contundencia la que permite que los estados consideren seriamente los argumentos planteados por la CIADH y, de esta forma, inicien un diálogo que tendrá particular relevancia en el contexto del proceso legislativo ${ }^{54}$. Tal como lo expresó recientemente el Juez Eduardo Vío, la autoridad de la Corte en relación a sus pronunciamientos consultivos se funda en "la sabiduría, imparcialidad y justicia" de sus decisiones ${ }^{55}$. Desde esa perspectiva, "la competencia no contenciosa o consultiva de la Corte no consiste (...) en ordenar (...) sino más bien en convencer" 56 .

\subsection{CONCLUSIÓN: SUBSIDIARIEDAD Y OPINIONES CONSULTIVAS}

Es posible comprender que existe una profunda relación entre las causales de inadmisibilidad establecidas por la CIADH para rechazar solicitudes de opinión consultiva y el carácter subsidiario del sistema regional de protección de derechos humanos. Desde esa perspectiva, y en términos generales, es posible afirmar que toda solicitud de opinión consultiva cuyo alcance fuerce a la Corte a emitir un pronunciamiento cuyo contenido implique alterar la estructura coadyuvante del sistema debe ser declarada inadmisible por aquella.

\section{APLICACIÓN DE LAS CAUSALES DE INADMISIBILIDAD DE LAS SOLICITUDES DE OPINIONES CONSULTIVAS Y NUEVAS TENDENCIAS JURISPRUDENCIALES EN LA CIADH}

La CIADH ha declarado inadmisibles cinco solicitudes de opinión consultiva planteadas por Costa Rica, la Comisión Interamericana de Derechos Humanos y el Secretario General de la Organización de Estados Americanos respectivamente. Es posible apreciar en dichas declaraciones de inadmisibilidad el interés de la Corte por custodiar el carácter subsidiario del sistema. Sin embargo, a partir de 1999, la CIADH ha desarrollado una línea jurisprudencial que no ha sido enteramente coherente con el interés referido. Ello en la medida que la Corte: (a) ha declarado admisibles solicitudes que le obligan a incursionar en el ámbito de las políticas públicas, y (b) ha afirmado el carácter jurídico vinculante de sus opiniones consultivas.

\subsection{Protección del Carácter subsidiario del sistema: declaraciones de INADMISIBILIDAD DE SOLICITUDES DE OPINIÓN CONSULTIVA}

\subsubsection{Los casos costarricenses}

La primera solicitud de opinión consultiva declarada inadmisible por la CIADH data de 1991. El caso en cuestión, sin embargo, no puede comprenderse adecuadamente sin conocer los hechos previos al mismo. Así, de acuerdo a la legislación costarricense existente al tiempo de la solicitud, el Código de Procedimientos Penales no preveía la posibili-

\footnotetext{
54 Pasqualucci (2012) p. 58.

55 Opinión Consultiva OC-24/17 "IDENTIDAd de GÉNERo, e IGUALdad y No Discriminación a Parejas del MisMO SEXO", voto individual del Juez Eduardo Vío Grossi, párrafo 154.

56 Opinión Consultiva OC-24/17 "IDENTIDAd de GÉNERo, e IGUALdAd y No DiscriminaCión a PARejas del MisMO SEXo", voto individual del Juez Eduardo Vío Grossi, párrafo 10.
} 
dad de ejercer el recurso de casación en contra de ciertas sentencias condenatorias, entre las que se encontraban aquellas que condenaban a la pena de prisión efectiva por un período de tiempo inferior a dos años. La imposibilidad de ejercer dicho recurso motivó una serie de presentaciones -nueve en total- ante la Comisión Interamericana de Derechos Humanos. En aquellas, las presuntas víctimas denunciaron al estado de Costa Rica por incurrir en la infracción del artículo 8.2 de la Convención, el cual consagraba el derecho al recurso.

Mientras la resolución de las denuncias en cuestión estaba pendiente ante la Comisión, y con el propósito de evitar una potencial condena por parte de los órganos del sistema interamericano, el ejecutivo costarricense presentó ante el Congreso un proyecto de ley que modificaba el Código de Procedimientos Penales. Dicha modificación permitía ejercer el recurso de casación en relación a todo tipo de sentencias condenatorias ante un nuevo tribunal establecido por ley. Una vez presentado el proyecto, el estado solicitó a la Corte emitir una opinión consultiva acerca de la compatibilidad del mismo con lo dispuesto en el artículo 8.2 de la Convención.

La CIADH decidió declarar inadmisible la solicitud de opinión consultiva por medio de la Opinión OC-12/91. Fundamentalmente, la Corte argumentó que el estado, por medio de su solicitud, buscaba obtener "una solución de manera encubierta, por la vía de la opinión consultiva, de asuntos litigiosos aún no sometidos a consideración de la Corte" 57 . En efecto, la Corte señaló que un pronunciamiento como el solicitado equivalía a resolver anticipadamente una cuestión de derechos humanos de carácter eminentemente litigioso, de forma tal que "un pronunciamiento de la Corte [en esta materia] podría eventualmente, interferir en casos que deberían concluir su procedimiento ante la Comisión en los términos ordenados por la Convención" 58 . De acuerdo a la CIADH, lo anterior contribuiría a afectar los derechos de los afectados, quienes carecerían de los mecanismos procesales adecuados para defender su posición ${ }^{59}$.

Como es posible apreciar, la Corte rechazó esta solicitud de Costa Rica en el entendido que la misma le obligaba a pronunciarse respecto de un caso esencialmente contencioso a través de la vía consultiva. Sin embargo, también es posible analizar la resolución del caso desde una perspectiva subsidiaria. Ello en la medida que la Corte, al restringir el ejercicio de su autoridad en este ámbito, reconoció el papel prioritario que desempeñan tanto los estados como la Comisión dentro del esquema de protección regional. Esto porque, por un lado, custodió la responsabilidad que le cabía a los tribunales nacionales de ser los primeros en conocer cualquier asunto litigioso de derechos humanos vinculado a la aplicación de la nueva ley. Por otro, protegió el papel de la Comisión, evitando emitir un pronunciamiento que podría haber influido indebidamente en la resolución de los casos pendientes ante aquella. Ciertamente todo esto permitió reforzar el carácter subsidiario del esquema de protección en la medida que la CIADH evitó asumir responsabilidades cuyo desempeño correspondía a otros actores del sistema.

\footnotetext{
57 Opinión Consultiva OC-12/91 “Compatibilidad de un proyecto de LEY CON EL ARTICULO 8.2.h DE LA CONVENCiÓN AMERICANA SOBRE DERECHOS HuMANOs”, párrafo 28.

58 Opinión Consultiva OC-12/91 "COMPATIBILIDAD DE UN PROYECTO DE LEY CON EL ARTÍCULO 8.2. h DE LA CONVENCIÓN AMERICANA SOBRE DERECHOS HuMANOS”, párrafo 29.

59 Opinión CONSUltiva OC-12/91 "COMPATIBILIDAD DE UN PROYECTO DE LEY CON EL ARTICULO 8.2. H DE LA CONVENCIÓN AMERICANA SOBRE DERECHOS HUMANOS”, párrafo 28.
} 
La CIADH volvió a declarar inadmisible otra solicitud de opinión consultiva de Costa Rica a través de una resolución de fecha 10 de mayo de 2005. Por medio de la señalada solicitud, el estado solicitó a la Corte pronunciarse respecto a la compatibilidad del artículo $9^{\circ}$ letra e) de la Ley de Personal de la Asamblea Legislativa con lo dispuesto en la Convención y en otros instrumentos de protección de derechos humanos del sistema.

En este caso concreto, el directorio de la Asamblea Legislativa había revocado la designación de algunos funcionarios de aquel poder del estado invocando el artículo $9^{\circ}$ letra e) de la Ley de Personal de la Asamblea Legislativa. Los afectados dedujeron, entonces, un recurso de reconsideración ante aquel directorio. Estando pendiente la resolución de dicho recurso, la Defensoría de los Habitantes presentó una acción de inconstitucionalidad ante la sala constitucional de la Corte Suprema, solicitando la declaración de inconstitucionalidad del precepto legal referido debido a su carácter discriminatorio. Dicha acción, sin embargo, fue rechazada por la sala constitucional en la medida que ella estimó que el precepto legal impugnado no infringía ningún tipo de derechos fundamentales.

A pesar de la decisión de la sala constitucional, la Asamblea Legislativa solicitó al Ejecutivo la presentación de una solicitud de opinión consultiva ante la CIADH. Todo esto para que la Corte volviera nuevamente a evaluar la legitimidad, desde la perspectiva de los derechos fundamentales, de la norma en cuestión. Ello fundado en el hecho que, a partir del voto de minoría de la sala constitucional, "había surgido una duda razonable sobre la veracidad de la tesis" ${ }^{\prime \prime 0}$ propuesta por la mayoría de los magistrados que integraban aquella sala. El estado argumentó ante la CIADH que un pronunciamiento definitivo del tribunal interamericano permitiría al directorio de la Asamblea Legislativa resolver el recurso de reconsideración pendiente con propiedad.

En este caso, la Corte declaró inadmisible la solicitud de opinión consultiva en la medida que pronunciarse respecto de la misma habría implicado afectar el carácter subsidiario del sistema de protección regional de derechos humanos. En efecto, la CIADH sugirió que la solicitud en cuestión recaía sobre una cuestión de derecho interno cuyo conocimiento parecía más propio de un tribunal nacional. De hecho, la propia CIADH afirmó tomar nota del hecho que "el estado busca[ba] que este tribunal se pronunci[ara] acerca de un punto sobre el cual (...) la sala constitucional ya se [había] pronunci[ado]"61. En ese sentido, pareciera que la Corte evitó asumir una responsabilidad que recaía eminentemente en la más alta magistratura nacional. Por otro lado, la CIADH volvió a afirmar que cualquier pronunciamiento respecto del objeto de análisis solicitado por el estado podría implicar resolver por vía consultiva una cuestión de suya contenciosa "aún no resuelt[a] a nivel interno ni sometid[a] a consideración de la Comisión o de la Corte" ${ }^{2}$. Con ello, la solicitud planteada por Costa Rica no hacía sino "desvirtuar la jurisdicción contenciosa" ${ }^{63}$ del tribunal interamericano.

En este caso, es posible apreciar cómo la CIADH evitó inmiscuirse en una discusión sobre derechos fundamentales sostenida entre los poderes del estado de Costa Rica. Con ello, la Corte no hizo sino proteger el carácter subsidiario del sistema regional, en la

60 RESOLUCIÓN DE 10 DE MAYO DE 2005, párrafo 10.

61 ReSOLUCIÓN DE 10 DE MAYO DE 2005, párrafo 12.

62 RESOLUCIÓN DE 10 DE MAYO DE 2005, párrafo 13.

63 RESOLUCIÓN DE 10 DE MAYO DE 2005, párrafo 13. 
medida que reconoció el papel prioritario que representan las instituciones nacionales en cuestiones litigiosas vinculadas a derechos fundamentales. Así lo reconocen, por ejemplo, Burgorgue-Larsen y Úbeda de Torres, quienes afirman que "si la Corte hubiese respondido la solicitud de Costa Rica, esto habría traído las más infortunadas consecuencias [para el sistema] (...) [ello porque] habría transformado a la CIADH en una corte de casación”64.

La experiencia de este último caso permite entender la dinámica de las opiniones consultivas en un contexto más amplio que el puramente jurídico. En efecto, detrás de las solicitudes de opiniones consultivas presentadas por los estados a la Corte se puede fácilmente ocultar un propósito que no es precisamente objetivo, esto es, un interés completamente aislado de la situación política interna del estado en cuestión ${ }^{65}$. Ello es aún más evidente si se considera que el Poder Ejecutivo es el único autorizado al interior del estado para solicitar opiniones consultivas a la CIADH. Desde esta perspectiva, es posible imaginar diversos tipos de casos en los que el Ejecutivo solicita una opinión consultiva a la Corte con fines espurios. Por ejemplo, casos en los que el Poder Ejecutivo utilice esta facultad con el propósito de manipular el proceso legislativo imponiendo su agenda política al Congreso, donde ese Ejecutivo no posee la mayoría suficiente para aprobar una iniciativa de ley que sea de su interés. Por otro lado, es posible también imaginar casos en los que el Ejecutivo busque, junto con el apoyo de otro poder del estado, debilitar la capacidad de decisión de alguna de las instituciones nacionales, como los tribunales de justicia.

Producto del accionar impropio del Poder Ejecutivo que solicita de forma indebida una opinión consultiva a la CIADH se puede derivar una afectación severa del esquema subsidiario del régimen de protección de derechos regional. Esto porque el Ejecutivo, incluso con el apoyo de otros poderes del estado, puede -en la práctica-, promover la transferencia de responsabilidades de autoridades nacionales a los órganos del sistema. Un ejemplo de ello es el segundo caso costarricense descrito en este apartado. En este caso, el Ejecutivo, apoyado por el Poder Legislativo, buscó forzar un pronunciamiento de la CIADH con el objeto de dejar sin efecto una sentencia dictada por la Corte Suprema que afirmaba la legitimidad de un precepto legal desde la perspectiva de los derechos fundamentales. De esa forma, el Ejecutivo costarricense buscó, en los hechos, transferir a la CIADH una responsabilidad que, dentro del sistema interamericano, correspondía al estado. La CIADH advirtió esta situación y correctamente declaró inadmisible la solicitud de opinión consultiva, protegiendo con ello la naturaleza coadyuvante del régimen de protección interamericano.

\subsubsection{Los casos de la Comisión Interamericana de Derechos Humanos}

Correspondió también a la CIADH declarar la inadmisibilidad de dos solicitudes de opinión consultiva presentadas por la Comisión Interamericana de Derechos Humanos. En ambos casos, la razón de la inadmisibilidad fue la misma: la Comisión solicitó que la Corte se pronunciara respecto de una materia sobre la cual el tribunal previamente había emitido opinión, con lo que la solicitud en cuestión carecía de relevancia. Mientras que en la primera solicitud la Comisión solicitó a la Corte pronunciarse respecto del alcance de su propia doctrina acerca de la imposición de la pena de muerte, en la segunda la Comisión

64 Burgorgue-Larsen y Úbeda de Torres (2011) p. 92. La traducción es nuestra.

65 Burgorgue-Larsen y Úbeda de Torres (2011) p. 92. 
solicitó a la Corte pronunciarse respecto de la doctrina desarrollada por la propia CIADH en relación con el principio del interés superior del niño.

En ambos casos, la CIADH destacó el hecho que tanto la Comisión como los estados se encontraban, respecto de las dos cuestiones objeto de análisis, en posición de interpretar y aplicar por sí mismos tanto la Convención como el cuerpo jurisprudencial desarrollado por la Corte en torno a las temáticas mencionadas. Por tanto, la CIADH no percibió como necesario emitir una nueva opinión en cada caso ${ }^{66}$.

Si bien la causal por las cual la Corte declaró inadmisible ambas opiniones consultivas parece ser, a primeras luces, puramente formal, ello no es del todo efectivo. Esto en la medida que la CIADH, a través de un ejercicio de autorrestricción, obligó en dos ocasiones a la Comisión a asumir sus propias responsabilidades dentro del sistema de protección. Con esto la Corte evitó que el ejercicio de aquellas responsabilidades fuera transferido a aquel tribunal. Dicha transferencia habría tenido carácter injusto porque, tal como la CIADH lo precisó, la Comisión se encontraba, en ambos casos, en perfectas condiciones de interpretar y aplicar tanto la Convención como la jurisprudencia de la Corte en estas materias. Luego, no había razón objetiva que justificara la intervención de la CIADH. En definitiva, a través de estas decisiones, la Corte fortaleció la estructura de subsidiariedad escalonada propia del sistema interamericano.

\subsubsection{El caso del Secretario General de la Organización de Estados Americanos (caso "Dilma")}

Recientemente, la CIADH declaró la inadmisibilidad de una solicitud de opinión consultiva presentada por el Secretario General de la Organización de Estados Americanos. Dicha solicitud estuvo motivada por el juicio político llevado adelante en Brasil contra la ex Presidenta Dilma Rousseff, el cual concluyó con su destitución. En efecto, el Secretario General solicitó a la Corte emitir un pronunciamiento consultivo en relación a "la legalidad de las causas invocadas para realizar el juicio político a la Presidente Dilma Rousseff [y sobre los] posibles vicios de derecho ocurridos (...)" ${ }^{67}$. Todo ello con el propósito de obtener un antecedente considerado necesario por el Secretario General para asumir las obligaciones impuestas a este por el artículo 20 de la Carta Democrática de la Organización de Estados Americanos ${ }^{68}$.

La CIADH declaró inadmisible la solicitud en la medida que una opinión consultiva en estas materias "podría constituir un pronunciamiento prematuro sobre el tema o asunto en cuestión, el que le podría ser sometido posteriormente en el marco de un caso contencioso" ${ }^{169}$. Sin embargo, la Corte conectó dicha idea con la necesidad de preservar el carácter coadyuvante del sistema interamericano al enfatizar, seguidamente, que cualquier opinión consultiva emitida en torno a este punto "podría implicar pronunciarse sobre un

\footnotetext{
66 RESOLUCIÓN DE 24 DE JUNIO DE 2005, párrafo 13; RESOLUCIÓN DE 27 DE ENERO DE 2009, párrafos 8-9.

67 RESOLUCIÓN DE 23 DE JUNIO DE 2016, párrafo 4.

68 RESOLUCIÓN DE 23 DE JUNIO DE 2016, párrafo 4.

69 RESOLUCIÓN DE 23 DE JUNIO DE 2016, párrafo 7.
} 
asunto que aún no ha[bía] sido resuelto a nivel interno"70. Ello, evidentemente, atentaría contra el carácter subsidiario del sistema regional, en la medida que el mismo entrega a los estados, en primer lugar, la responsabilidad de proveer mecanismos eficaces para la protección de derechos fundamentales. Por tanto, habría resultado contrario a esa lógica que la CIADH hubiese asumido, en primer lugar, la responsabilidad de resolver la cuestión planteada por el Secretario General de la Organización de Estados Americanos.

La defensa del carácter subsidiario del sistema por parte de la CIADH en este caso es evidente. El Secretario General de la Organización de Estados Americanos buscó, por medio de la obtención de una opinión consultiva, una decisión que permitiera legitimar jurídicamente una suerte de intervención en asuntos internos de un estado. Todo ello utilizando el lenguaje propio de los derechos. En este caso, la Corte protegió la naturaleza coadyuvante del sistema recordando al Secretario General que, en caso de haber existido algún tipo de infracción de derechos en el proceso de impeachment que afectó a la Presidenta Rousseff, la responsabilidad de resolver la cuestión correspondía, en primer lugar a las autoridades nacionales, particularmente a los tribunales de justicia. En ese sentido, esta decisión de la CIADH se asemeja a aquella que recayó sobre el segundo caso costarricense mencionado anteriormente dentro de este apartado. En efecto, el Secretario General, por medio de su solicitud de opinión consultiva, buscó transferir a la CIADH responsabilidades que correspondían a las autoridades nacionales. Al igual que en el caso señalado, la CIADH asumió la defensa del carácter subsidiario del sistema y declaró la inadmisibilidad de la solicitud.

\section{NUEVAS TENDENCIAS DE LA CIADH EN RELACIÓN A LAS OPINIONES CONSULTIVAS: EVIDENCIANDO CONTRADICCIONES}

En el apartado previo en este trabajo, hemos analizado cómo la CIADH ha buscado custodiar el carácter subsidiario del sistema regional de protección de derechos por medio del establecimiento y aplicación de una serie de causales de inadmisibilidad que permiten a la Corte rechazar solicitudes de opinión consultiva. Sin embargo, es posible advertir nuevas tendencias en la jurisprudencia de la CIADH a partir de 1999. Dichas tendencias no son completamente coherentes con la doctrina desarrollada por la propia Corte en relación a esta materia ${ }^{71}$. Ello en la medida que las nuevas tendencias aparecen en fuerte tensión con las exigencias propias de la subsidiariedad.

\subsection{Opiniones CONSUltivas CON ALCANCE GENERAL: SEŃALANDO POlíticas PÚblicas a LOS ESTADOS}

A partir de 1999, la CIADH ha declarado admisibles una serie de solicitudes de opinión consultiva en las cuales diversos estados o la Comisión requieren de la Corte un pronunciamiento de alcance genérico que especifique políticas públicas en torno a cuestiones

\footnotetext{
70 RESOLUCIÓN DE 23 DE JUNIO DE 2016, párrafo 7.

71 En relación a otras situaciones en que la CIADH no ha sido suficientemente consistente con criterios jurisprudenciales desarrollados por ella misma, puede verse: CANDIA (2015).
} 
como el derecho a la información de asistencia consular ${ }^{72}$, la condición jurídica y derechos humanos del niño ${ }^{73}$, la condición jurídica y derechos de los migrantes indocumentados ${ }^{74}$, los derechos y garantías de niñas y niños en situación de migración ${ }^{75}$, y la regulación jurídica de las parejas homosexuales ${ }^{76}$.

En los referidos casos la CIADH ha emitido opiniones consultivas de alcance amplio, refiriendo una serie de lineamientos generales y específicos que deben ser implementados por los estados. Todo ello en el entendido que, en relación a estas materias, existía un déficit de políticas públicas al interior de aquellos.

Si bien es laudable que la Corte busque proteger, por ejemplo, los derechos de las niñas y niños o de los migrantes, es necesario que ello se realice a través de los mecanismos y en las formas establecidas por la Convención. Tal como la propia CIADH lo ha señalado, es deber de la Corte "garantizar la protección internacional que establece la Convención [respecto de los derechos] dentro de la integridad del sistema pactado por los estados" ${ }^{\prime 7}$. En ese sentido, es posible encontrar serias tensiones entre las exigencias sustantivas de la subsidiariedad y el pronunciamiento de opiniones consultivas con alcance general. En efecto, si bien existe un acuerdo amplio respecto al reconocimiento de los derechos, por ejemplo, de niñas, niños y migrantes, es perfectamente lógico que puedan existir desacuerdos respecto de las políticas públicas específicas que implementen las exigencias de aquellos derechos ${ }^{78}$. En ese sentido, si la CIADH impone esas políticas a los estados, lo que hace es asumir en parte responsabilidades que, en principio, corresponden a las comunidades políticas nacionales, limitando con ello el margen de apreciación reconocido en favor de aquellas.

La problemática descrita aparece referida por el Juez Oliver Jackman en su voto disidente contenido en la Opinión Consultiva OC-17/02. En este caso concreto, la Comisión Interamericana de Derechos Humanos solicitó a la Corte "la formulación de criterios generales válidos sobre [la condición jurídica y los derechos de los niños] dentro del marco de la Convención Americana"79. Dado el tenor de esta petición, el Juez Jackman se mostró favorable a declarar su inadmisibilidad.

Ello por dos razones específicas. En primer lugar, la solicitud en cuestión planteaba una consulta redactada en términos tales que la misma "carec[ía] de significación" ${ }^{80}$. Una segunda razón tuvo carácter más institucional. En efecto, el Juez Jackman afirmó que la CIADH era un órgano esencialmente judicial y, por tanto, debía abstenerse de emitir pro-

\footnotetext{
72 OPINIÓN CONSULTIVA OC-16/99 "EL DERECHO A LA INFORMACIÓN SOBRE LA ASISTENCIA CONSULAR EN EL MARCO DE LAS GARANTIAS DEL DEBIDO PROCESO”.

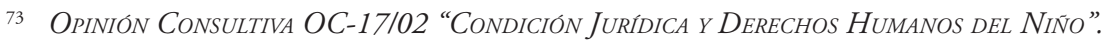

74 OPINIÓN CONSULTIVA OC-18/03 “CONDICIÓN JURIDICA Y DERECHOS DE LOS MiGRANTES INDOCUMENTADOS”.

75 OPINIÓN CONSULTIVA OC-21/14 "DERECHOS Y GARANTIAS DE NIÑAS Y NIÑOS EN EL CONTEXTO DE LA MIGRACIÓN Y/O EN NECESIDAD DE PROTECCIÓN INTERNACIONAL.

76 Opinión Consultiva OC-24/17 "Identidad de GÉNero, e IGUALdad y No Discriminación a Parejas del MisMO SEXO".

77 Asunto ViVIANA GALLARDo (1981), párrafo 16.

78 Sobre este punto, véase: Sunstein (1996) pp. 35-38.

79 Opinión Consultiva OC-17/02 “Condición Jurídica y DeREChos Humanos del NiÑo”. Voto disidente del Juez Oliver Jackman, p. 2.

80 Opinión Consultiva OC-17/02 “Condición JuRÍdica Y DeRechos Humanos del Niño". Voto disidente del Juez Oliver Jackman, p. 2.
} 
nunciamientos respecto de solicitudes de opinión consultiva que constituyeran "pura especulación académica, sin una previsible aplicación a situaciones concretas que justifiquen el interés de que se emita [aquella]" 81 . Para el Juez Jackman, la solicitud de criterios generales válidos efectuada por la Comisión representaría, precisamente, un ejemplo de pura especulación académica en la medida que la solicitud "no se encontraría justificada en la necesidad de una urgencia pública, ni se trataría de una cuestión jurídica compleja" ${ }^{22}$. Para el Juez Jackman la decisión de la CIADH que declaró la admisibilidad de la solicitud en cuestión "no h[izo] sino debilitar el sistema establecido por la Convención (...) distorsiona[ando con ello] la jurisdicción consultiva de la Corte" ${ }^{\prime 3}$.

Es perfectamente posible hacer una lectura de este voto disidente en clave subsidiaria. Para el Juez Jackman, la CIADH era un órgano judicial, y como tal, debía estar preferentemente abocado a la resolución de casos concreto. . Ahora bien, para el Juez Jackman, el carácter eminentemente judicial de la CIADH debía influir la forma como este tribunal ejercía su función consultiva. En efecto, de acuerdo al criterio señalado, las opiniones consultivas debían recaer sobre cuestiones particulares que le fuesen presentadas por los estados u otros órganos del sistema. Desde esta perspectiva, no sería propio de la función consultiva dictar lineamientos de política pública, cuestión que sería incompatible con el carácter jurisdiccional de la CIADH. Solo esta lectura permite entender por qué al final de su disidencia, el Juez Jackman afirmó que la declaración de admisibilidad de este tipo de solicitudes de opinión consultiva "debilita[ban] el sistema establecido por la Convención" ${ }^{44}$. Ese debilitamiento se encontraría, precisamente, en la afectación del carácter subsidiario del esquema de protección regional. Esto último en la medida que la CIADH, a través de la dictación de políticas públicas por medio de opiniones consultivas, asumiría responsabilidades que de suyo corresponden a los propios estados. Ello contradice las doctrinas propuestas por la propia Corte acerca de la naturaleza y alcance de las opiniones consultivas ${ }^{85}$.

\subsection{EFECTOS DE OPINIONES CONSUlTIVAS: UN GIRO EN LA DOCTRINA DE LA CIADH}

Otra línea jurisprudencial desarrollada por la CIADH que contradice la doctrina planteada por la propia Corte en relación a la necesidad de asegurar la subsidiariedad del sistema regional en materia de opiniones consultivas es la que otorga alcance general y

\footnotetext{
81 Opinión Consultiva OC-17/02 “Condición Jurídica y Derechos Humanos del Niño". Voto disidente del Juez Oliver Jackman, p. 2.

82 Opinión Consultiva OC-17/02 “Condición Jurídica y Derechos Humanos del Niño”. Voto disidente del Juez Oliver Jackman, p. 2.

83 Opinión Consultiva OC-17/02 “Condición Jurídica y Derechos Humanos del Niño”. Voto disidente del Juez Oliver Jackman, p. 2.

84 Opinión Consultiva OC-17/02 “Condición Jurídica y Derechos Humanos del Niño”. Voto disidente del Juez Oliver Jackman, p. 2.

85 Similar problemática fue recientemente identificada por el Juez Vío en su voto individual a propósito de lo dispuesto por la CIADH en su Opinión Consultiva OC-24/17. De acuerdo al juez en cuestión, el ejercicio de la función consultiva no autoriza a la Corte a imponer a los estados políticas públicas específicas en relación al matrimonio. En relación a este punto, el Juez Vío manifestó que el artículo 17 de la Convención Americana entregaba a los estados, y no a la CIADH, la facultad de "determin[ar] las condiciones para contraer matrimonio y fundar una familia”. Véase: OPINIÓN CONSULTIVA OC-24/17 "IDENTIDAD DE GÉNERO, E IGUALDAD Y NO DISCRIMInación a Parejas del Mismo SeXo”, voto individual del Juez Eduardo Vío Grossi, párrafo 106.
} 
obligatorio a aquellas. Era doctrina permanente de la Corte afirmar que las opiniones consultivas, pese "a [sus] efectos jurídicos innegables" ${ }^{\circ 6}$,"no [tenían] el carácter vinculante de

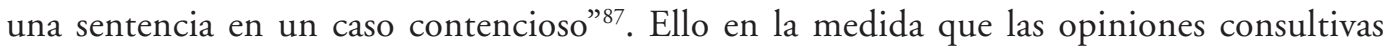
representa[ban] mecanismos a través de los cuales se buscaba "asesorar y ayudar a los estados (...) para que cumpl[ieran] de manera cabal y efectiva sus obligaciones internacionales [en materia de derechos humanos]" 88 .

Sin embargo, la doctrina de la Corte con relación a este punto comenzó a variar a partir del pronunciamiento de la Opinión Consultiva OC-21/14. En la señalada opinión, la CIADH reafirmó la obligación de todos los órganos estatales de aplicar el control de convencionalidad dentro de sus jurisdicciones, debiendo utilizar como parámetro del mismo no solo las interpretaciones de la Convención efectuadas por la Corte en el contexto de la resolución de casos contenciosos, sino también aquellas interpretaciones contenidas en opiniones consultivas $^{89}$. Esto último en razón de que ambas jurisdicciones compartían el propósito de "prote[ger] los derechos fundamentales de los seres humanos" ${ }^{0}$. En este mismo sentido se pronunció la Opinión Consultiva OC-22/16, la cual derechamente indicó que "las opiniones consultivas cumplen (...) la función propia de un control de convencionalidad preventivo" ${ }^{11}$. De forma similar, la Corte en su última opinión consultiva -la Opinión Consultiva OC-24/17- manifestó que todos los estados del sistema y los órganos de la Organización de Estados Americanos tienen la obligación de efectuar un control de convencionalidad fundado en sus opiniones consultivas ${ }^{92}$. Ello en la medida que la CIADH representaba la "intérprete última de la Convención Americana"93. En los últimos dos casos referidos -las Opiniones Consultivas OC-22/16 y OC-24/17- la Corte invocó como fun-

\footnotetext{
86 OPINIÓN CONSULTIVA OC-16/99 "EL DERECHO A LA INFORMACIÓN SOBRE LA ASISTENCIA CONSULAR EN EL MARCO DE LAS GARANTIAS DEL DEBIDO PROCESO”, párrafo 48.

87 OPINIÓN CONSULTIVA OC-16/99 "EL DERECHO A LA INFORMACIÓN SOBRE LA ASISTENCIA CONSULAR EN EL MARCO DE LAS GARANTIAS DEL DEBIDO PROCESO”, párrafo 48.

88 Opinión Consultiva OC-1/82 “Otros tratados" objeto de la función CONSUltiva de la Corte (artículo 64 DE LA CONVENCIÓN AMERICANA SOBRE DERECHOS HuMANOS), párrafo 23.

89 OPINIÓN CONSULTIVA OC-21/14 "DERECHOS Y GARANTIAS DE NINAAS Y NIÑOS EN EL CONTEXTO DE LA MIGRACIÓN Y/O EN NECESIDAD DE PROTECCIÓN INTERNACIONAL”, párrafo 31.

90 OPINIÓN CONSUltiva OC-21/14 "DeRECHOS Y GARANTIAS DE NIÑAS Y NIÑOS EN EL CONTEXTO DE LA MIGRACIÓN Y/O EN NECESIDAD DE PROTECCIÓN INTERNACIONAL”, párrafo 31.

91 Opinión Consultiva OC-22/16 "Titularidad DE DERECHOS DE LAS PERSONAS JURÍdiCAS EN EL Sistema INTERAMERICANO DE DERECHOS HUMANOS (INTERPRETACIÓN Y ALCANCE DEL ARTICULO 1.2, EN RELACIÓN CON LOS ARTICULOS 1.1,

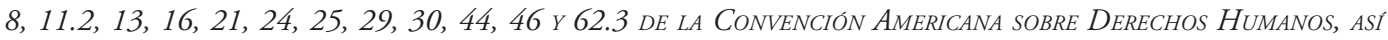
COMO DEL ARTYCULO 8.1.A Y B DEL PROTOCOLO DE SAN SALVADOR)", párrafo 26.

92 Opinión Consultiva OC-24/17 "Identidad de Género, e IGUaldad y No Discriminación a Parejas del MisMO SEXO", párrafo 26.

93 Opinión Consultiva OC-24/17 "IDENTIDAd de GÉNERo, e IgUaldad y No Discriminación a Parejas del MisMO SEXO", párrafo 16. Dicho reconocimiento de supremacía judicial ya había sido esbozado por la Corte en su Opinión Consultiva OC-20/09, en la cual se afirmó que "la intérprete última de la Convención Americana" era, específicamente, la CIADH. Véase: OPINIÓN CONSULTIVA OC-20/09 "ARTÍCULO 55 DE LA CONVENCIÓN AMERICANA SOBRE DERECHOS HuMANOs", párrafo 18.
} 
damento normativo de su supremacía lo resuelto anteriormente en los casos contenciosos ALmonacid Arellano v. Chile ${ }^{94}$ y Chinchilla Sandoval y otros v. GUatemala ${ }^{95}$.

La nueva doctrina de la CIADH, que transformó las opiniones consultivas en mecanismos de control de convencionalidad, es receptiva de ciertas tesis propuestas por autores partidarios de reconocer efectos jurídicos obligatorios a aquellas. Por ejemplo, para Faúndez, cuando la Corte pronuncia opiniones consultivas lo hace en su calidad de órgano jurisdiccional del sistema interamericano y no como un órgano asesor ${ }^{96}$. En cuanto tal, las resoluciones de la Corte que buscan interpretar la Convención u otros tratados de derechos humanos, y aquellas que se pronuncian respecto de la convencionalidad de la legislación nacional no representarían meras asesorías que la CIADH ofrece a los estados, sino "dictámenes" ${ }^{97}$ cuyo contenido es obligatorio para los estados que los solicitan. Esto en la medida que dichos dictámenes son emitidos por el órgano judicial del sistema, único facultado para interpretar de forma auténtica el contenido de la Convención ${ }^{98}$. De hecho, Faúndez va incluso más allá: este autor plantea que cuando la CIADH se pronuncia en torno a la compatibilidad de la legislación nacional, lo haría ejerciendo las facultades propias de un tribunal constitucional ${ }^{99}$. En ese mismo sentido, Ruiz plantea que las características propias del ejercicio de la función consultiva de la Corte permitían considerar a la misma "como crisálida de una futura jurisdicción supraconstitucional"100. Para Salvioli, esta interpretación es la única que permitiría dotar de eficacia a los derechos contenidos en la Convención en el contexto del ejercicio de la función consultiva de la Corte ${ }^{101}$. Por otro lado, Nikken afirma que cuando la CIADH emite una opinión consultiva lo hace en el ejercicio de sus facultades jurisdiccionales y, por tanto, las opiniones también revestirían carácter jurisdiccional. Luego, las mismas tendrían similar fuerza vinculante que las sentencias pronunciadas por la Corte en el ejercicio de su jurisdicción contenciosa ${ }^{102}$.

Desde esta perspectiva, y a partir de lo señalado tanto por la CIADH como por la doctrina referida, es posible afirmar que la Corte ha buscado dotar a sus opiniones consultivas de fuerza jurídica obligatoria. Esto último no solo en relación a los estados o los órganos que las solicitaron, sino también en relación a todos los estados partes del siste$\mathrm{ma}^{103}$.

La doctrina planteada por la Corte es opuesta a aquella expresada de forma reiterada por la CIADH en sus opiniones consultivas previas, en las que este tribunal reforzó el carácter orientador de su jurisdicción consultiva. En efecto, existe una diferencia entre

\footnotetext{
94 Opinión Consultiva OC-20/09 “Artículo 55 de la Convención Americana sobre Derechos Humanos”, párrafo 18.

95 Opinión Consultiva OC-24/17 "IDEntidad de Género, e Igualdad y No Discriminación a Parejas del MisMO SEXO", párrafo 16.

96 Faúndez (2004) p. 991.

97 FAÚNDEZ (2004) p. 991

98 FAÚNDEZ (2004) p. 991

99 FAÚNDEZ (2004) pp. 991-992.

100 Ruiz (1998) p. 1.360.

101 Salvioli (2004) p. 42.

102 NiKKen (1998) p. 171.

103 Almonacid Arellano y otros V. Chile (2006) párrafo 124.
} 
una opinión que busca, esencialmente, proveer una guía no vinculante a la acción de los estados, y otra que es jurídicamente obligatoria. En el primer caso, los estados disponen de un amplio margen de apreciación para decidir acerca de la implementación de la norma interpretada por la Corte en su opinión consultiva. Evidentemente, existe una obligación para los estados que solicitan una opinión consultiva de considerar seria e integralmente la interpretación propuesta por la Corte y los criterios derivados de aquella. Es a partir de esa obligación de consideración que se debe generar un diálogo entre CIADH y los estados. Sin embargo, la existencia de esa obligación no debe oscurecer el hecho que son los propios estados los últimos llamados a aplicar la Convención dentro de sus jurisdicciones. Por tanto, y tal como lo planteara el Juez Vío, el ejercicio de la función consultiva por parte de la CIADH "no debe transformarse en el ejercicio de la función normativa, la que, en general, está expresamente conferida a los estados"104. Es precisamente por esto que, tratándose de la implementación de opiniones consultivas, los estados disponen de un amplio margen de apreciación reconocido por la misma CIADH.

Sin embargo, en el segundo caso las opiniones consultivas consideradas como expresión del control de convencionalidad los estados no gozan de ese mismo margen de apreciación. Ello en la medida que la implementación del contenido de las opiniones sería obligatorio no solo para el estado que solicitó la opinión, sino también para la totalidad de los estados y órganos del sistema regional. En ese contexto, y aplicando la doctrina Almonacid, no existiría real espacio para el disenso. Luego, no habría cabida para un margen de apreciación materialmente significativo en favor de los estados ${ }^{105}$. La tendencia jurisprudencial descrita en este apartado, en torno a las opiniones consultivas, contradice la doctrina tradicional de la propia Corte en relación a esta materia, en la medida que aquella realiza en mucho menor medida las exigencias propias de la subsidiariedad en esta área.

\section{CONCLUSIÓN}

La CIADH ha establecido una serie de causales de inadmisibilidad en relación a las solicitudes de opinión consultiva que pueden efectuar tanto los estados como los demás órganos del sistema. Por medio de la aplicación de las mismas, la CIADH ha custodiado el carácter orientador de su función consultiva y el carácter subsidiario del sistema regional de protección de derechos humanos. Sin embargo, la CIADH ha generado a partir de 1999 una serie de líneas jurisprudenciales en torno a las opiniones consultivas que no son completamente coherentes con la doctrina anteriormente desarrollada por la Corte en estas materias, cuestión que necesariamente afecta el carácter subsidiario del sistema.

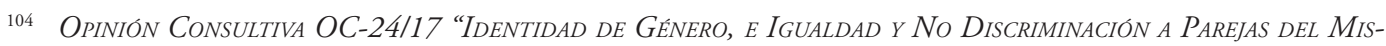
MO SEXO”, Voto individual del Juez Eduardo Vío Grossi, párrafo 7.

105 Ruiz-Chiriboga (2010) p. 203. 


\section{BIBLIOGRAFÍA CITADA}

Besson, Samantha (2016): "Subsidiarity in international human rights law What is subsidiary about human rights?”, The American Journal of Jurisprudence, vol. 61, No. 1: pp. 69-107.

Burgorgue-Larsen, Laurence y Úbeda de Torres, Amaya (2011): The Inter-American Court of Human Rights. Case law and commentary (Oxford, Oxford University Press).

Candia, Gonzalo (2015): "El estado de derecho y la Corte Interamericana de Derechos Humanos", Dikaion, Vol. 24, N²: pp. 225-252.

Donoho, Douglas Lee (2003): "Democratic legitimacy in human rights: the future of international decision-making", Wisconsin International Law Journal, Vol. 21: pp. 1-64.

FAúndeZ, Héctor (2004): El sistema interamericano de protección de los derechos humanos. Aspectos institucionales y procesales (San José de Costa Rica, Instituto Interamericano de Derechos Humanos, tercera edición).

FinNis, John (2016): "Subsidiarity's roots and history: some observations", The American Journal of Jurisprudence, Vol. 61, No. 1: pp. 133-141.

GREGG, Andrew (2012): The margin of appreciation in international human rights law (Oxford, Oxford University Press).

Hessler, Kristen (2005): "Resolving interpretative conflicts in international human rights law", The Journal of Political Philosophy, No. 1: pp. 29-52.

HitTers, Juan Carlos (2008): “¿Son vinculantes los pronunciamientos de la Comisión y de la Corte Interamericana de Derechos Humanos? (control de constitucionalidad y convencionalidad), Revista Iberoamericana de Derecho Procesal Constitucional, $\mathrm{N}^{\circ}$ 10: pp. 131-156.

Mowbray, Alastair (2015): "Subsidiarity and the European Convention on Human Rights”, Human Rights Law Review, Vol. 15: pp. 313-341.

NikKen, Pedro (1998): "La función consultiva de la Corte Interamericana de Derechos Humanos", en Secretaría de la Corte Interamericana de Derechos Humanos (edit.), Liber amicorum Héctor Fix-Zamudio, Tomo I (San José de Costa Rica, Corte Interamericana de Derechos Humanos) pp. 161-181.

Pasqualucci, Jo M. (2012): The practice and procedure of the Inter-American Court of Human Rights (New York, Cambridge University Press, segunda edición).

PAúl, Álvaro (2017): "Rechazo de solicitudes de opinión consultiva por parte de la Corte Interamericana de Derechos Humanos", Revista Chilena de Derecho y Ciencia Politica, Vol. 8 No.1: 119-131.

Ruiz, Carlos (1998): "La función consultiva en el sistema interamericano de derechos humanos: ¿Crisálida de una jurisdicción supra-constitucional?”, en SECRETARÍA DE LA Corte Interamericana de Derechos Humanos (edit.), Liber amicorum Héctor Fix-Zamudio, Tomo III (San José de Costa Rica, Corte Interamericana de Derechos Humanos) pp. 1.345-1.363.

Ruiz-Chiriboga, Oswaldo (2010): "The conventionality control: examples of (un)successful experiences in Latin America”, Inter-American and European Human Rights Journal, Vol. 3, No. 1 y 2: pp. 200-219. 
SAlvioli, Fabián (2004): "La competencia consultiva de la Corte Interamericana de Derechos Humanos: marco legal y desarrollo jurisprudencial", en Homenaje y reconocimiento a Antônio Cançado Trindade, Tomo III (Brasilia, Editorial Sergio Fabris) pp. 417-472.

Sunstein, Cass (1996): Legal reasoning and political conflict (Oxford, Oxford University Press).

WaLdRon, Jeremy (1999): Law and disagreement (Oxford, Oxford University Press).

\section{NORMAS CITADAS}

Convención Americana sobre Derechos Humanos, suscrita en la conferencia especializada Interamericana sobre derechos humanos, 7-22 de noviembre de 1969, Pacto de San José de Costa Rica.

Carta Democrática Interamericana, suscrita por la Asamblea General de la Organización de Estados Americanos, 11 de septiembre de 2001.

Ley No. 4.556 (08/05/1970), Ley de personal de la Asamblea Legislativa de Costa Rica.

\section{JURISPRUDENCIA CITADA}

Sentencias de la Corte Interamericana de Derechos Humanos

Almonacid ARELlano y otros V. Chile. Excepciones preliminares, fondo, reparaciones y costas. Sentencia de 26 de septiembre de 2006. Serie C Nº 154.

Caso las Palmeras v. Colombia. Fondo. Sentencia de 2 de diciembre de 2001. Serie C No 90.

Caso Acevedo Jaramillo v. Perú. Interpretación de la sentencia de excepciones preliminares, fondo, reparaciones y costas. Sentencia de 24 de noviembre de 2006. Serie C No 157.

Caso Cabrera García y Montiel Flores V. MéxiCo. Excepción preliminar, fondo, reparaciones y costas. Sentencia de 26 de noviembre de 2010. Serie C No 220.

Palma MENDOZA y OtROS V. ECUADOR. Excepción preliminar y fondo. Sentencia de 3 de septiembre de 2012. Serie C No 247.

RÍOS Y OTROS V. VENEZUELA. Excepciones preliminares, fondo, reparaciones y costas. Sentencia de 28 de enero de 2009. Serie C No 194.

Opiniones Consultivas de la Corte Interamericana de Derechos Humanos

"Otros tratados" objeto de la función consultiva de la Corte (artículo 64 de la Convención Americana sobre Derechos Humanos), OC-1/82, 24 de septiembre 1982 (Serie A) No 1 (1982).

"Restricciones a la pena de muerte (artículos 4.2 y 4.4 de la Convención Americana sobre Derechos Humanos)", OC-3/83, 8 de septiembre 1983 (Serie A) No 3 (1983).

"Propuesta de modificación a la Constitución Política de Costa Rica relacionada con la naturalización", OC-4/84, 19 de enero 1984 (Serie A) No 4 (1984).

"La expresión leyes en el artículo 30 de la Convención Americana sobre derechos humanos", OC-6/86, 9 de mayo 1986 (Serie A) Nº (1986). 
"Compatibilidad de un proyecto de ley con el artículo 8.2.h de la Convención Americana sobre Derechos Humanos", OC-12/91, 6 de diciembre de 1991 (Serie A) No 12 (1991).

"Ciertas atribuciones de la Comisión Interamericana de Derechos Humanos (artículos 41, 42, 44, 46, 47, 50 y 51 de la Convención Americana sobre Derechos Humanos)", OC 13/93, 16 de julio 1993 (Serie A) No. 13 (1993).

"Responsabilidad internacional por expedición y aplicación de leyes violatorias de la Convención (artículos $1^{\circ}$ y $2^{\circ}$ de la Convención Americana sobre Derechos Humanos)", OC-14/94, 9 de diciembre 1994 (Serie A) No 14 (1994).

"El derecho a la información sobre la asistencia consular en el marco de las garantías del debido proceso”, OC-16/99, 1 de octubre 1999 (Serie A) No 16 (1999).

"Condición jurídica y derechos humanos del niño", OC-17/02, 28 de agosto 2002 (Serie A) $\mathrm{N}^{\circ} 17$ (2002).

"Condición juridica y derechos de los migrantes indocumentados", OC-18/03, 17 de septiembre 2003 (Serie A) No 18 (2003).

"Artículo 55 de la Convención Americana sobre Derechos Humanos", OC-20/09, 29 de septiembre de 2009 (Serie A) No 20 (2009).

"Derechos y garantías de niñas y niños en el contexto de la migración y/o en necesidad de protección internacional", OC-21/14, 19 de agosto 2014 (Serie A) N²1 (2014).

"Titularidad de derechos de las personas jurídicas en el sistema interamericano de derechos humanos (interpretación y alcance del artículo 1.2, en relación con los artículos 1.1, 8, 11.2, 13, 16, 21, 24, 25, 29, 30, 44, 46 y 62.3 de la Convención Americana sobre Derechos Humanos, así como del artículo 8.1.A y B del Protocolo de San Salvador)", OC-22/16, 26 de febrero 2016 (Serie A) No 22 (2016).

"Identidad de Género, e Igualdad y No Discriminación a Parejas del Mismo Sexo", OC-24/17, 24 de noviembre de 2017 (Serie A) No 24 (2017).

\section{Resoluciones de la Corte Interamericana de Derechos Humanos}

ASUNTO VIVIANA GALLARDO, 13 de noviembre de 1981.

RESOLUCiÓN SOBRE SOLICITUd DE OPINIÓN CONSULTIVA PRESENTADA POR LA REPÚBLICA DE COSTA RICA, 10 de mayo de 2005.

RESOLUCIÓN SOBRE SOLICITUD DE OPINIÓN CONSULTIVA PRESENTADA POR LA COMISIÓN INTERAMERICANa DE DeREChos Humanos, 24 de junio de 2005.

RESOLUCIÓN SOBRE SOLICITUD DE OPINIÓN CONSULTIVA PRESENTADA POR LA COMISIÓN INTERAMERICANA DE DeREChos Humanos, 27 de enero de 2009.

RESOLUCIÓN SOBRE SOLICITUD DE OPINIÓN CONSULTIVA PRESENTADA POR EL SECRETARIO GENERAL DE LA ORGANIZACIÓN DE Estados AmERICANOS, 23 de junio de 2016. 